\title{
On the Appropriate Transformation Technique and Model Selection in Forecasting Economic Time Series: An Application to Botswana GDP Data
}

D. K. Shangodoyin

University of Botswana, shangodoyink@mopipi.ub.bw

K. Setlhare

University of Botswana, setlharek@mopipi.ub.bw

K. K. Moseki

University of Botswana, mpsekikk@mopipi.ub.bw

K. Sediakgotla

University of Botswana, sediakgotla@mopipi.ub.bw

Follow this and additional works at: http://digitalcommons.wayne.edu/jmasm

Part of the Applied Statistics Commons, Social and Behavioral Sciences Commons, and the Statistical Theory Commons

\section{Recommended Citation}

Shangodoyin, D. K.; Setlhare, K.; Moseki, K. K.; and Sediakgotla, K. (2010) "On the Appropriate Transformation Technique and Model Selection in Forecasting Economic Time Series: An Application to Botswana GDP Data," Journal of Modern Applied Statistical Methods: Vol. 9 : Iss. 1 , Article 28.

DOI: $10.22237 /$ jmasm/1272688020

Available at: http://digitalcommons.wayne.edu/jmasm/vol9/iss1/28

This Regular Article is brought to you for free and open access by the Open Access Journals at DigitalCommons@WayneState. It has been accepted for inclusion in Journal of Modern Applied Statistical Methods by an authorized editor of DigitalCommons@WayneState. 


\title{
On the Appropriate Transformation Technique and Model Selection in Forecasting Economic Time Series: An Application to Botswana GDP Data
}

\author{
D. K. Shangodoyin \\ K. Setlhare K. K. Moseki \\ K. Sediakgotla \\ University of Botswana, \\ Botswana
}

Selected data transformation techniques in time series modeling are evaluated using real-life data on Botswana Gross Domestic Product (GDP). The transformation techniques considered were modified, although reasonable estimates of the original with no significant difference at $\alpha=0.05$ level were obtained: minimizing square of first difference (MFD) and minimizing square of second difference (MSD) provided the best transformation for GDP, whereas the Goldstein and Khan (GKM) method had a deficiency of losing data points. The Box-Jenkins procedure was adapted to fit suitable ARIMA (p, d, q) models to both the original and transformed series, with AIC and SIC as model order criteria. ARIMA (3, $1,0)$ and ARIMA $(1,0,0)$ were identified, respectively, to the original and log of the transformed series. All estimates of the fitted stationary series were significant and provided a reliable forecast.

Key words: Data transformation technique, autoregressive integrated moving average, model order criteria, forecast, gross domestic product.

\section{Introduction}

The foremost difficulty with economic research in developing countries is the dearth of data. Much of the available economic time series data are constructed out of bits and pieces that must be shaped and arranged to yield a final series that is useable for model building. One way to circumvent this problem is to estimate some components for dates for which time series is not readily available from known values of that component for other dates For example, the US real Gross Domestic Product (GDP) and German real GDP are produced and publicly released at quarterly intervals, although both US and German economic analysts and business-

D. K. Shangodoyin is Associate Professor at the Department of Statistics. Email: shangodoyink@mopipi.ub.bw. K. Setlhare is Senior Lecturer at the Department of Statistics. Email: setlharek@mopipi.ub.bw. K. K. Moseki is a Lecturer at the Department of Statistics. Email: mpsekikk@mopipi.ub.bw. K. Sediakgotla is a Lecturer at the Department of Statistics. Email: sediakgotla@mopipi.ub.bw. decision makers often need monthly GDP forecasts (Stum \& Wollmershauser, 2005), quarterly figures may be required only when the series of annual data are available. This problem has led to several transformations of the data to the form required by researchers for particular research objectives. Economists use many transformations of time series data to help extract economically relevant information (Cohen, 2001).

A facet of the research conducted focuses on the interpolation of some values of a series at a given time period by a related series (Friedman, 1962). The problem with this technique is that it assumes that a related series as well as some values of the series to be interpolated - are readily available: this may not be the case in developing countries. Various studies have been concerned with the derivation of quarterly figures from annual data, including Lisman and Sandee (1964), Boot, et al. (1967) and Goldstein \& Khan (1976); in each of these examples the value of a quarterly figure for each year $t$, is considered as a weighted average of the totals of the years. A system of equations is built from which weighted coefficients were calculated subject to some criteria. 
The challenge, therefore, is to explore the efficiency of the transformation techniques and analyze their prediction potential. Some transformation techniques can be found in Boot, et al. (1967) which introduced two methods that involve minimizing the squared first differences (MSFD) and minimizing the squared second differences (MSSD). Goldstein and Khan (1976) proposed an interpolation technique based on the quadratic function: the transformed data could be modeled appropriately by checking the order of the fitted model using model order selection criteria as discussed by Shibata (1976).

In this article, the focus is to evaluate the efficacy of data transformation techniques with the aim of using two known models' order determination criteria to produce the best model order-transformation technique for forecasting economic time series with application to Botswana GDP data. This is considered a challenge to analysts in view of the dearth of quarterly economic series data in some sectors of a nation's economy where only annual data is available.

\section{Methodology}

The Technique and Model Determination

Boot, et al. (1967) considered two procedures for the interpolation of quarterly figures given only annual data; the basis of their research is the work of Lisman \& Sandel (1964). The first approach is based on the criterion that minimizes the sum of square of the first difference (MFD) between the successive quarterly values, which are subject to the constraint that, each year, the sum of the quarterly total should equal the yearly totals.

Mathematically, consider $\mathrm{n}$ years for which it is necessary to minimize $\sum_{i=2}^{4 n}\left(x_{i}-x_{i-1}\right)^{2} \quad$ subject to $\sum_{i=4 t-3}^{4 k} x_{i}=y_{t}$ for $t=1,2, \ldots n$ where $x_{i}$ is the $i^{\text {th }}$ quarterly total and $y_{t}$ is the given yearly total in year $t$. The problem can be solved by using the Langrangean expression:

$$
\sum_{i=2}^{4 n}\left(x_{i}-x_{i-1}\right)^{2}-\sum_{k=1}^{n} \lambda_{t}\left(\sum_{i=4 t-3}^{4 t} x_{i}-y_{t}\right) .
$$

The MFD derived formula for calculating the estimated quarterly total within three successive years is given as:

$$
\left(\begin{array}{l}
x_{1 i} \\
x_{2 i} \\
x_{3 i}
\end{array}\right)=\frac{1}{1836}\left(\begin{array}{l}
\mathbf{X}_{11} \\
\cdots \cdots \\
\mathbf{X}_{\mathbf{1 2}} \\
\cdots \cdots \\
\mathbf{X}_{\mathbf{1 3}}
\end{array}\right)\left(\begin{array}{l}
\mathbf{y}_{t-\mathbf{1}} \\
\mathbf{y}_{t} \\
\mathbf{y}_{t+1}
\end{array}\right)
$$

where $x_{k i}$ is the estimated quarterly value in years $k=1,2,3$ and quarters $i=1,2,3,4$, $t=1,2,3,4$ and $\mathbf{y}_{t-\mathbf{1}}, \mathbf{y}_{t}, y_{t+1}$ are the totals for the three successive years, and

$$
\begin{aligned}
& \mathbf{X}_{11}=\left(\begin{array}{ccc}
569 & -135 & 25 \\
525 & -87 & 15 \\
437 & 27 & -5 \\
305 & 189 & -35
\end{array}\right), \\
& \mathbf{X}_{12}=\left(\begin{array}{ccc}
129 & 405 & -75 \\
7 & 513 & -61 \\
-61 & 513 & 7 \\
-75 & 405 & 129
\end{array}\right), \\
& \mathbf{X}_{13}=\left(\begin{array}{ccc}
-35 & 189 & 305 \\
-5 & 27 & 437 \\
15 & -187 & 525 \\
25 & -135 & 569
\end{array}\right) .
\end{aligned}
$$

The second approach is the minimization of the sum of square of the second difference (MSD) in which $\sum_{i=2}^{4 n}\left(\Delta x_{i}-\Delta x_{i-1}\right)^{2}$, is minimized, where $\Delta x_{i}=x_{i+1}-x_{i}$, is subject to the constraint $\quad \sum_{i=4 t-3}^{4 t} x_{i}=y_{t} \quad t=1,2, \ldots n$, $t=1,2, \ldots n$, and the $x_{i}{ }^{\prime} s$ are as defined above. Similar to the MSFD, the problem is solved by considering the Lagrangean expression 


\section{SHANGODOYIN, SETLHARE, MOSEKI \& SEDIAGOTLA}

$\sum_{i=2}^{4 n}\left(\Delta x_{i}-\Delta x_{i-1}\right)^{2}-\sum_{t=1}^{n} \lambda_{k}\left(\sum_{i=4 t-3}^{4 t} x_{i}-y_{t}\right)$, which

- when solved routinely for $n=3$ - was shown to give the solution:

$$
\left(\begin{array}{l}
x_{1 i} \\
x_{2 i} \\
x_{3 i}
\end{array}\right)=\frac{1}{9280}\left(\begin{array}{l}
\mathbf{X}_{21} \\
\cdots \cdots \\
\mathbf{X}_{22} \\
\cdots \cdots \\
\mathbf{X}_{23}
\end{array}\right)\left(\begin{array}{l}
\mathbf{y}_{t-1} \\
\mathbf{y}_{t} \\
\mathbf{y}_{t+1}
\end{array}\right)
$$

where the $x_{k i}$ and the $y^{\prime} s$ are defined as previously and

$$
\begin{aligned}
& \mathbf{X}_{21}=\left(\begin{array}{lll}
3499 & -1488 & 309 \\
2697 & -464 & 87 \\
1911 & 528 & -119 \\
1173 & 1424 & -227
\end{array}\right), \\
& \mathbf{X}_{22}=\left(\begin{array}{rrr}
531 & 2128 & -338 \\
49 & 2512 & -241 \\
-241 & 2512 & 49 \\
-339 & 2128 & 531
\end{array}\right), \\
& \mathbf{X}_{23}=\left(\begin{array}{rrr}
-277 & 1424 & 1173 \\
-119 & 528 & 1911 \\
87 & -464 & 2697 \\
309 & -1488 & 3499
\end{array}\right) .
\end{aligned}
$$

Goldstein and Khan (1976) (GKM) proposed an interpolation technique for converting annual totals to quarterly series by using the quadratic functions passing through three successive points $y_{\mathbf{t}-\mathbf{1}}, y_{\mathbf{t}}$ and $y_{t}$ the expressions for these interpolations are:

$$
\begin{aligned}
& 0.0548 y_{\mathbf{t}-\mathbf{1}}+0.2343 y_{\mathbf{t}}-0.0390 y_{\mathbf{t}+\mathbf{1}} \\
& 0.0077 y_{\mathrm{t}-1}+0.2657 y_{\mathbf{t}}-0.0235 y_{\mathbf{t}+1} \\
& 0.0100 y_{\mathbf{t}-\mathbf{1}}+0.2500 y_{\mathbf{t}}-0.01500 y_{\mathbf{t}+\mathbf{1}} \\
& 0.0400 y_{\mathbf{t}-\mathbf{1}}+0.2400 y_{t}-0.0110 y_{\mathbf{t}+\mathbf{1}}
\end{aligned}
$$

In the expressions, the first year will have $y_{\mathbf{t}-\mathbf{1}}=y_{\mathbf{t}}=0$ and the second year will have $y_{\mathbf{t}-\mathbf{1}}=0$ in the computation of the quarterly total for the years, assuming $y_{t-1}, y_{t}$ and $y_{t+1}$ are independent aggregates. Lisman and Sandel (1964) assumed that the quarterly data, for example, $\mathbf{Z}_{\mathbf{J}}$, was linearly dependent on three successive annual totals and proposed the computation of quarterly data from the following:

$$
\left(\begin{array}{ccc}
0.0729 & 0.1982 & -0.0211 \\
-0.0103 & 0.3018 & -0.0415 \\
-0.0415 & 0.3018 & -0.0103 \\
-0.0211 & 0.1982 & 0.0729
\end{array}\right)\left(\begin{array}{l}
\mathbf{y}_{t-1} \\
\mathbf{y}_{t} \\
\mathbf{y}_{t+1}
\end{array}\right)
$$

All of these methods are known to have limitations (Boot, et al., 1967), thus other mathematical methods of interpolation have been developed by researchers such as Glejer (1966), Boots and Feibes (1967) and Vangrevelinghe (1966). The choice of method as described in (i)-(iv) is based on the similarity in their computation. It would be of tremendous assistance to analysts if the various methods are subjected to real-life data experimentation, while the transformed data are modeled with an appropriate check on the models order to ascertain their suitability in forecasting.

In this article it is assumed that the y's are moving by 3 points, models are run up to n2, and the identified (or fitted) model is used to compute $\mathbf{n - 1}$ and $\mathbf{n}$ so that no year is omitted and the model provides a reasonable degree appropriateness for the transformed data. The Box-Jenkins modeling was performed on both the original and transformed data with a view to forecast. However, the unknown value of the model order, $\mathbf{P}$, may constitute a casualty in modeling as attempts to under fit increases the residual variance, while over fitting results in too many parameters which eventually causes unreliability (Jones, 1975; Shibata, 1976). Various selection criteria have been advanced for model order selection (Box, Jenkins \& Reinsel, 1994), in this article, three similar 
criteria were employed vis-à-vis the Akaike information criteria (AIC) $\left\{\mathbf{N} \ln \sigma_{\mathbf{p}}^{2}+2 p\right\}$, final predictor error (FPE) $\left\{\left(\frac{N+p}{N-p}\right) \sigma_{p}^{2}\right\}$ and Schwarz's criterion (SIC) $\left\{\mathbf{N} \ln \sigma_{\mathbf{p}}^{2}+\mathbf{P} \ln \mathbf{N}\right\}$. The order in which two of these criteria agree shall be considered to be the best order for the data.

\section{Results}

Data Analysis: Transformation and Modeling of Botswana GDP Data

Data presented in Appendix I shows that no significant variation exists between the average values of data computed by the three techniques and the original data. The test of difference conducted between the original series and the transformed series indicates that there is no significant difference between the means of the GDP, MFD, MSD and GKM. It was observed (see Appendix II), that the MFD and MSD provided the best transformation for the Botswana GDP data while the GKM had a deficiency of losing data points. The proposed method of moving point incorporated into the selected techniques is shown to be worthwhile because neither the MFD nor the MSD lost any data.

\section{Model Selection and Order Determination}

The original GDP series is made stationary by taking the first difference (see Appendix II) - an autoregressive process of order 3 is identified as the most suitable model. Based on AIC and SIC criteria, the fitted values (Appendix II) are adequate as indicated in Figure 2 and the bounds placed on the fitted values appear to have accommodated the original values adequately.

The MFD, MSD and GKM series became stationary only when the logtransformation was taken, the AIC, SIC and model RESIDUALS were the criteria used in selecting the best order for the model and these identified the AR (1) models to MFD, MSD and GKM. The behavior of the fitted values (see Appendix III, Figures 1-4 and Tables 1--4) indicate the appropriateness of the model as confirmed by the Portmanteaux test for model adequacy.

\section{Conclusion}

The moving point method introduced into the transformation techniques utilized in this research has shown a tremendous improvement over the MFD and MSD. It was observed that both MFD and MSD give nearly the same fitted values as the original series; thus confirming the findings of Shangodoyin and Adubi (2000) who used Nigeria GDP data. The choice of the model order should not, however, be limited to the order determination criteria but also to the model residual variance.

\section{References}

Boot, J. C. G., et al. (1967). Further method of derivation of quarterly figures from annual data. J.R.S.S. Series C, 16(1), Vo.16. 6575.

Box, G. E. P., Jenkins, G. M., \& Reinsel, G. C. (1994). Time series analysis: Forecasting and control, $\left(3^{\text {rd }} E d\right.$.). New Jersey: Prentice Hall.

Cohen, D. (2001). Linear transformation used in economics. Washington DC: Federal Reserve Board.

Friedman, M. (1962). The interpolation of time series by related series. J.A.S.A., 57(300), 729-757.

Glejser, H. (1966). Une methode d'evaluation de donnees menuelles a partir d'indices trimestriels ou annuels. Cahiers Economiques de Bruxelles, 19(1), 45.

Goldstein, \& Khan. (1976). An analysis of transformation revisited. J.A.S.A..76, 296311.

Jones, R. H. (1975). Fitting autoregressions. J.A.S.A., 70, 590-592.

Lisman, J. H., \& Sandee, J. (1964). Derivation of quarterly figures from annual data. Applied Statistics, 13, 87-90.

Shangodoyin, D. K., \& Adubi, A. A. (2000). Appropriate data transformation techniques in forecasting economic series: A case study of Nigeria GDP. Nigerian Statistical Association Conference, Floria Nigeria.

Shibata, R. C. (1976). Selection of the order of an autoregressive model by Akaike's information criterion. Biometrika, 63, 117-126. 
Stum, J-E., \& Wollmershauser, T. (2005). IFO survey data in business cycle and monetary policy analysis. Springer International handbook of education, Volume. 13.
Vangrevelinghe, G. (1966). Levolution a court terme de la consummation des ménages. Etudes et Conjoncture (INSEE), 9, 54-102.

Appendix I: One-Way Analysis of Variance

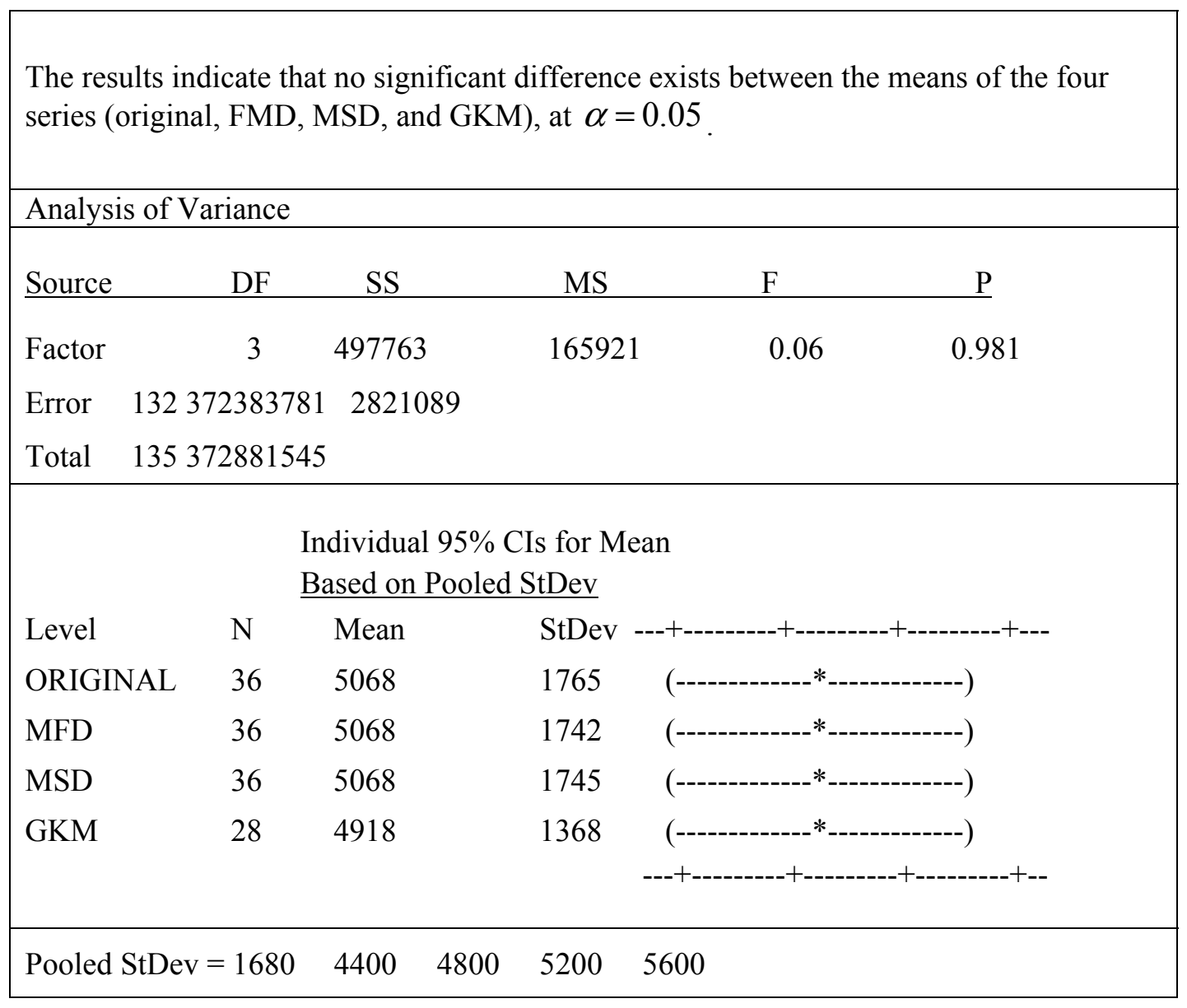


TRANSFORMATION \& MODEL SELECTION: FORECASTING TIME SERIES GDP DATA

Appendix II: Original and Transformed Series with Forecast Values

\begin{tabular}{|c|c|c|c|c|c|c|c|}
\hline Actual GDP & MFD & MSD & GKM & $\begin{array}{l}\text { Fitted GDP } \\
\text { Values }\end{array}$ & $\begin{array}{c}\text { Fitted MFD } \\
\text { Values }\end{array}$ & $\begin{array}{c}\text { Fitted MSD } \\
\text { Values }\end{array}$ & $\begin{array}{l}\text { Fitted GKM } \\
\text { Values }\end{array}$ \\
\hline 2918.5 & 2713.68 & 2669.984 & 2924.033 & NA & NA & NA & NA \\
\hline 2633 & 2732.35 & 2728.983 & 3009.161 & NA & 2812.433 & 2766.022 & 3049.796 \\
\hline 2667.8 & 2769.68 & 2789.227 & 2962.78 & NA & 2913.945 & 2864.974 & 3178.91 \\
\hline 2822 & 2825.68 & 2853.205 & 3228.221 & NA & 3018.262 & 2966.907 & 3311.378 \\
\hline 2964.8 & 2900.35 & 2924.651 & 3308.047 & 3310.34 & 3125.433 & 3071.894 & 3447.203 \\
\hline 2959.3 & 2996.24 & 3008.543 & 3451.497 & 3004.924 & 3235.503 & 3180.005 & 3586.381 \\
\hline 3074.2 & 3113.37 & 3107.371 & 3407.489 & 2939.061 & 3348.52 & 3291.311 & 3728.91 \\
\hline 3263.4 & 3251.74 & 3221.135 & 3704.262 & 3311.223 & 3464.531 & 3405.888 & 3874.781 \\
\hline 3469.9 & 3411.33 & 3347.346 & 4148.561 & 3598.809 & 3583.582 & 3523.809 & 4023.983 \\
\hline 3330.3 & 3531.03 & 3481.024 & 4349.12 & 3559.041 & 3705.721 & 3645.149 & 4176.504 \\
\hline 3325.3 & 3610.82 & 3618.437 & 4274.65 & 3369.796 & 3830.992 & 3769.985 & 4332.328 \\
\hline 4078.4 & 3650.72 & 3757.094 & 4604.015 & 3554.994 & 3959.443 & 3898.395 & 4491.436 \\
\hline 4540.1 & 4308.45 & 4172.611 & 4856.836 & 4346.209 & 4091.118 & 4030.458 & 4653.806 \\
\hline 4280.4 & 4359.09 & 4349.4 & 4987.995 & 4649.145 & 4226.064 & 4166.252 & 4819.415 \\
\hline 4385 & 4460.37 & 4524.359 & 4895.197 & 4367.403 & 4364.324 & 4305.858 & 4988.234 \\
\hline 4534.7 & 4612.29 & 4693.829 & 5311.871 & 4600.11 & 4505.945 & 4449.359 & 5160.236 \\
\hline 4894.5 & 4814.85 & 4852.319 & 5175.132 & 4762.759 & 4650.971 & 4596.837 & 5335.387 \\
\hline 5107.8 & 4986.19 & 4992.512 & 5287.936 & 5018.153 & 4799.445 & 4748.376 & 5513.653 \\
\hline 4861.9 & 5126.32 & 5110.746 & 5208.404 & 5225.658 & 4951.41 & 4904.06 & 5694.997 \\
\hline 5298.3 & 5235.24 & 5207.023 & 5697.818 & 5064.246 & 5106.911 & 5063.975 & 5879.38 \\
\hline 5614.1 & 5312.94 & 5285.001 & 5906.844 & 5501.775 & 5265.99 & 5228.209 & 6066.761 \\
\hline 5937.3 & 5371.21 & 5352 & 6120.156 & 5749.231 & 5428.688 & 5396.848 & 6257.095 \\
\hline 4578.2 & 5410.06 & 5413.51 & 6021.465 & 6074.464 & 5595.048 & 5569.981 & 6450.337 \\
\hline 5394.1 & 5429.49 & 5473.19 & 6532.291 & 4770.482 & 5765.11 & 5747.699 & 6646.438 \\
\hline 6144.7 & 6059.24 & 5875.95 & 6831.44 & 5582.387 & 5938.915 & 5930.091 & 6845.349 \\
\hline 6444.7 & 6129.85 & 6116.536 & 7050.604 & 6288.624 & 6116.503 & 6117.25 & 7047.018 \\
\hline 5856.1 & 6271.08 & 6356.419 & 6929.72 & 6593.752 & 6297.914 & 6309.268 & 7251.391 \\
\hline 6497.6 & 6482.93 & 6594.195 & 7519.338 & 6040.774 & 6483.185 & 6506.238 & 7458.412 \\
\hline 7144.8 & 6765.39 & 6827.755 & NA & 6676.607 & 6672.355 & 6708.256 & 7668.025 \\
\hline 7009.6 & 7035.87 & 7054.289 & NA & 7295.269 & 6865.461 & 6915.416 & NA \\
\hline 6906.9 & 7294.36 & 7272.392 & NA & 7165.869 & 7062.54 & 7127.815 & NA \\
\hline 7575.2 & 7540.87 & 7482.064 & NA & 7085.977 & 7263.628 & 7345.549 & NA \\
\hline 7794.8 & 7775.39 & 7684.71 & NA & 7748.615 & 7468.76 & 7568.718 & NA \\
\hline 7269.2 & 7951.28 & 7883.141 & NA & 7950.03 & 7677.97 & 7797.419 & NA \\
\hline 7924.1 & 8068.55 & 8079.464 & NA & 7429.783 & 7891.292 & 8031.753 & NA \\
\hline 8934.4 & 8127.18 & 8275.084 & NA & 8099.146 & 8108.759 & 8271.82 & NA \\
\hline
\end{tabular}


SHANGODOYIN, SETLHARE, MOSEKI \& SEDIAGOTLA

Appendix III: Graphs and Tables Results

Table 1: GDP at Constant 1993/94 Prices in P'000 000

\begin{tabular}{|c|c|c|c|}
\hline Stationary & First Difference & & \\
\hline Identified Model & & ARIMA(p,1,0) & \\
\hline Order of Model & 1 & 2 & 3 \\
\hline $\mathrm{c}$ & $179.8878(68.48002)$ & $165.8992(33.4594)$ & $166.0609(21.4485)$ \\
\hline $\mathrm{a} 1$ & $-0.1669(0.1812)$ & $-0.3379(0.1551)$ & $-0.6071(0.1753)$ \\
\hline $\mathrm{a} 2$ & $\mathrm{na}$ & $-0.6494(0.1560)$ & $-0.8321(0.1583)$ \\
\hline $\mathrm{a} 3$ & $\mathrm{na}$ & $\mathrm{na}$ & $-0.4559(0.1802)$ \\
\hline $\mathrm{AIC}$ & 15.1775 & 14.808 & 14.6707 \\
\hline SIC & 15.2673 & 4346325 & 3431744 \\
\hline Residual Var & 6909122 & & 14.8539 \\
\hline Best Model: & \multicolumn{2}{|c|}{$D(G D P)=166.0609-0.6071 X_{t-1}-0.8321 X_{t-2}-0.45589 X_{t-3}$} \\
\hline$A R I M A(3,1,0)$ & $\hat{X}_{t+m=}=166.0609+G D P(-1)-0.6071 G D P(-1)-0.8321 G P D(-2)-0.45589 G D P(-3)$ \\
\hline Forecasting Model
\end{tabular}

Table 2: Table 2: Results of Fitted Model on MFD Series

\begin{tabular}{|c|c|c|c|}
\cline { 2 - 4 } \multicolumn{1}{c|}{} & \multicolumn{3}{c|}{ MFD } \\
\hline $\begin{array}{c}\text { Stationary } \\
\text { Montified } \\
\text { Model }\end{array}$ & 1 & ARIMA (p, 0, 0) & \\
\hline Order of Model & $12.3638(7.2757)$ & $11.6372(4.2104)$ & $11.1797(2.8020)$ \\
\hline c & $0.992(0.015)$ & $0.8208(0.1756)$ & $0.7673(0.1828)$ \\
\hline a1 & na & $0.1674(0.1753)$ & $0.0979(0.2312)$ \\
\hline a2 & na & na & $0.11859(0.1811)$ \\
\hline a3 & -4.098 & -4.066 & -4.02 \\
\hline AIC & -4.009 & -3.932 & 0.027209 \\
\hline SIC & 0.03066 & 0.028598 & \\
\hline Residual Var & \multicolumn{3}{c|}{$\log (M F D)=12.3636+0.992 M F D(-1)$} \\
\hline $\begin{array}{c}\text { Best Model: } \\
\text { ARIMA(1,1,0) }\end{array}$ & $\widehat{X}_{t+m}=\exp (12.3636+0.992 M F D(-1))$ \\
\hline $\begin{array}{c}\text { Forecasting } \\
\text { Model }\end{array}$ & \multicolumn{3}{c}{} \\
\hline
\end{tabular}


Appendix III: Graphs and Tables Results (continued)

Figure 1: Forecast and MFD Values

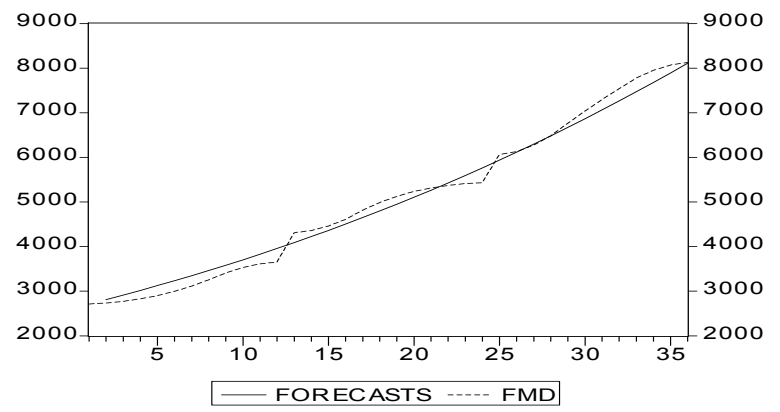

Figure 2: Forecast And GDP Values

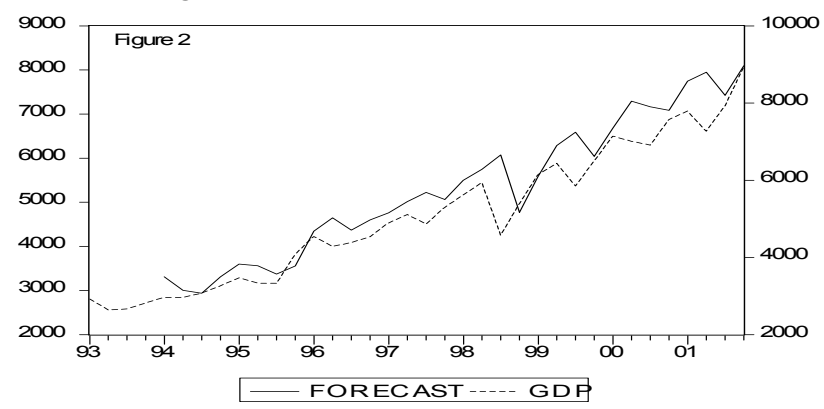

Table 3: Results of Fitted Model on MSD Series

\begin{tabular}{|c|c|c|c|}
\cline { 2 - 4 } \multicolumn{1}{c|}{} & \multicolumn{3}{c|}{ MSD } \\
\hline Stationary & $\begin{array}{c}\text { Logarithm } \\
\text { Transformation }\end{array}$ & ARIMA(p,0,0) & \\
\hline Identified Model & & 2 & 3 \\
\hline Order of Model & 1 & $11.844(4.2843)$ & $10.7887(2.4542)$ \\
\hline c & $14.502(9.4691)$ & $1.2938(0.1696)$ & $1.2326(0.1822)$ \\
\hline a1 & $0.9947(0.0084)$ & $-0.3006(0.1690)$ & $-0.0995(0.2917)$ \\
\hline a2 & na & na & $-0.1419(0.1803)$ \\
\hline a3 & na & -5.2796 & -5.222 \\
\hline AIC & -5.252 & -5.1449 & -5.0412 \\
\hline SIC & -5.163 & 0.08501 & 0.008718 \\
\hline Residual Variance & 0.009471 & $\log (S M D)=14.502+0.9947 S M D(-1))$ \\
\hline Best Model & \multicolumn{2}{|c|}{$\widehat{X}_{t+m}=\exp (14.502+0.9947 S M D(-1))$} \\
\hline Forecasting Model & \multicolumn{2}{c}{} \\
\hline
\end{tabular}

Figure 3: Forecast and MSD Values

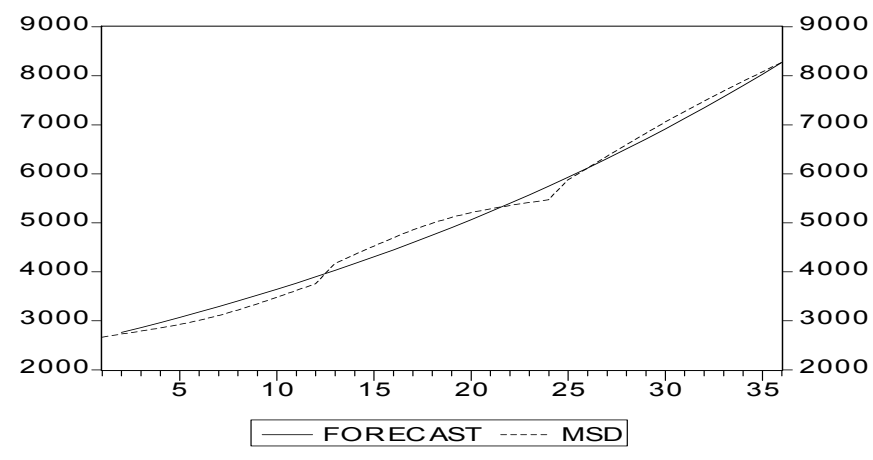

Figure 4: Forecast and Values Of GKM

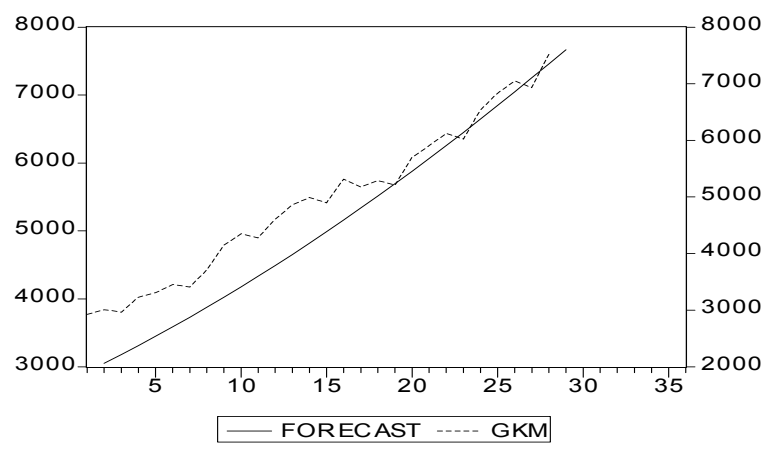


SHANGODOYIN, SETLHARE, MOSEKI \& SEDIAGOTLA

Appendix III: Graphs and Tables Results (continued)

Table 4: Results of Fitted Model on GKM Series

\begin{tabular}{|c|c|c|c|}
\cline { 2 - 4 } \multicolumn{1}{c|}{} & \multicolumn{3}{c|}{ GKM } \\
\hline Stationary & $\begin{array}{c}\text { Logarithm } \\
\text { Transformation }\end{array}$ & ARIMA(p,0,0) & \\
\hline Identified Model & & 2 & 3 \\
\hline Order of Model & 1 & $10.7123(3.4997)$ & $9.9587(1.2735)$ \\
\hline $\mathrm{c}$ & $10.7201(4.4355)$ & $0.6679(0.2054)$ & $0.5865(0.2058)$ \\
\hline $\mathrm{a} 1$ & $0.9846(0.0298)$ & $0.3118(0.2022)$ & $0.1671(0.2498)$ \\
\hline $\mathrm{a} 2$ & na & na & $0.2078(0.2084)$ \\
\hline $\mathrm{a} 3$ & na & -3.399 & -3.433 \\
\hline AIC & -3.4161 & -3.2537 & -3.2381 \\
\hline SIC & -3.3201 & 0.040382 & 0.034315 \\
\hline Residual Variance & 0.044768 & $\log (G K M)=10.7201+0.9846 G K M(-1))$ \\
\hline Best Model & \multicolumn{2}{|c|}{$\widehat{X}_{t+m}=\exp (10.7201+0.9846 G K M(-1))$} \\
\hline
\end{tabular}

